Vol. LXV 2014

\title{
ANALYSIS OF VAPOUR LIQUID EQUILIBRIA IN UNCONVENTIONAL RICH LIQUID GAS CONDENSATE RESERVOIRS
}

\author{
SZYMON KUCZYŃSKI \\ Faculty of Drilling. Oil and Gas / Natural Gas Engineering Department \\ AGH University of Science \& Technology in Kraków, Poland, szymon.kuczynski@agh.edu.pl
}

\begin{abstract}
At the beginning of 21st century, natural gas from conventional and unconventional reservoirs has become important fossil energy resource and its role as energy fuel has increased. The exploration of unconventional gas reservoirs has been discussed recently in many conferences and journals. The paper presents considerations which will be used to build the thermodynamic model that will describe the phenomenon of vapour liquid equilibrium (VLE) in the retrograde condensation in rocks of ultra-low permeability and in the nanopores. The research will be limited to "tight gas" reservoirs (TGR) and "shale gas" reservoirs (SGR). Constructed models will take into account the phenomenon of capillary condensation and adsorption. These studies will be the base for modifications of existing compositional simulators.
\end{abstract}

Key words: unconventional natural gas, gas condensate, capillary condensation, adsorption, shale

\section{Introduction}

It is said that surface interactions in the porous media may be important in the very narrow capillary radius in the micropores. The fully thermodynamic analyse of reservoir hydrocarbon system is impossible because of large influence of factors (see e.g. Nagy 2002, 2003). The traditional attitude to flat vapour-liquid thermodynamics may be extended to curved surfaces with gravity and adsorption/capillary condensation components. The new effects related to critical phenomena in narrow pores will be important for vapour- liquid equilibrium in tight and shale rocks (Nagy 2013).

\section{Capillary effects}

The capillarity and gravity segregation effects on the PVT and vapour liquid equilibria (VLE) properties of the reservoir fluid are omitted in the classical thermodynamic analysis. The variation of reservoir temperature in the system is passed over, although the last analysis confirms the necessity to include these effects in some cases. In some cases characteristics of porous-media equilibrium conditions the influence of interface curvature should be taken into account. In the range of laboratory PVT-VLE research the additional effect of capillarity is omitted in the case of the saturation phase envelope (Nagy, S. 2002). 
Figure 1. Schematic impact of adsorption-capillary effects near phase boundary (dew curve): 1-monolayer adsorption, 2-multilayer adsorption, 3-capillary condensation, 4-bulk condensation

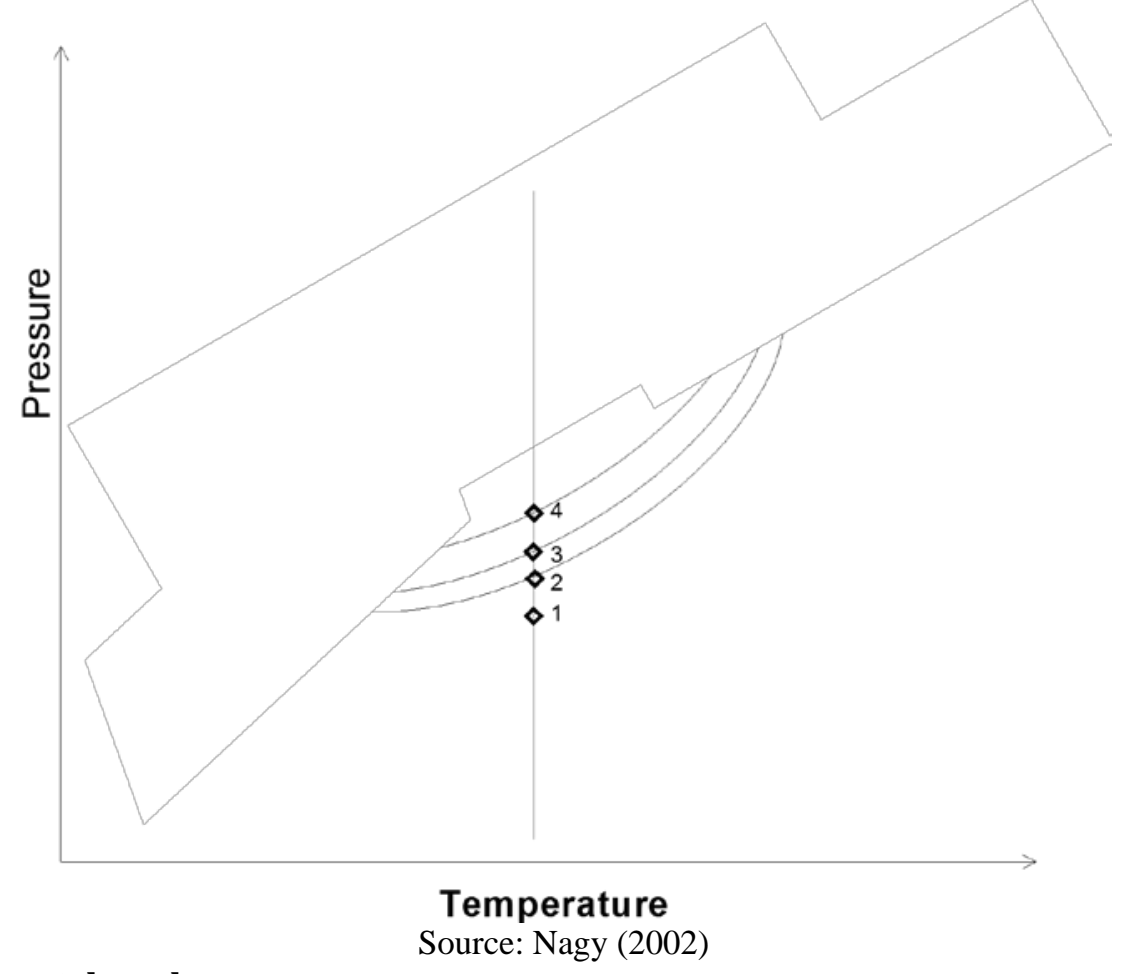

\subsection{Experimental work}

Source: Nagy (2002)

The Russian authors Trebin and Zadora (1968) reported a strong influence of the porous media on the dew-point pressure and vapour-liquid equilibria (VLE) of the condensate system. The porous media used in this experiment was a silica-sand mixture $(0.215 / 0.3 \mathrm{~mm}$ diameter $)$ ground by a cutter-pulverizer. They used three samples with surface area respectively 563, 1307 and $3415 \mathrm{~cm}^{2}$, permabilities $5.6 \mu \mathrm{m}^{2}$, $61210^{-3} \mu^{2}, 11110^{-3} \mu \mathrm{m}^{2}$ and porosities 34, 31.4 and $29.8 \%$. According to the conclusions from this paper the dew-point pressure increases when the surface area of the porous media increases. The observed effect was a $10-15 \%$ increase of the dew-point pressure in this system. The observed effect was lessened when the temperature increased.

Other researches indicate that there is no evidence of influence of average capillary porous media on the saturation pressure. Weinaug and Cordell's (1949) work shows that for the methane-n butane and ethane-n pentane system there is no difference due to the presence of sand in the PVT cell. Oxford and Huntington (1953) showed that during the evaporation of n-hexane during nitrogen injection there was no significant effect on the porous media. Smith and Yarborough (1968) indicate in their paper about wettability that the porous structure has little impact on the vaporisation process of the liquid phase in the rock.

Sigmund et al. (1974) analysed the laboratory work done by Trebin and Zadora and they concluded that the main reason for the hypothetical impact of the porous structure on the saturation pressure was the lack of fluid circulation in the cell. They performed an analogy experiment with fluid flow through core in the PVT cell.

The simple comparison of the average porous radius of model sandstone rock using a modified Kozeny-Carman equation is given in table 1 .

It is evident that capillarity effects may be noticeable at a pore-radius of $10^{-5} \mathrm{~cm}$. This condition limits the investigation area to porous rocks below $110^{-3} \mu \mathrm{m}^{2}(1 \mathrm{mD})$.

The capillary effects observed by the Trebin and Zadora researches may be caused by accompanying laboratory effects (Nagy 2002). 
Table 1: The comparison of permeability of rock with average hydraulic porous radius using modified Cozeny-Karman equation. It was assumed $20 \%$ of effective porosity of rock.

\begin{tabular}{|c|c|}
\hline $\mathbf{k}[\mathbf{m d}]$ & $\mathbf{r}[\mathbf{c m}]$ \\
\hline 0.1 & $6.3 \mathrm{E}-06$ \\
\hline 1 & $2.0 \mathrm{E}-05$ \\
\hline 10 & $6.3 \mathrm{E}-05$ \\
\hline 100 & $2.0 \mathrm{E}-04$ \\
\hline 1000 & $6.3 \mathrm{E}-04$ \\
\hline 10000 & $2.0 \mathrm{E}-03$ \\
\hline
\end{tabular}

Source: Nagy (2002)

\section{Adsorption phenomena in porous rocks}

The adsorption phenomena in porous media may have a significant impact on the reservedistribution of oil and gas fields, coal-beds or geothermal reservoirs. Papers by Economides (1986) and Satik, Horne and Yortsos (1995) suggests the possibility to cover up to $85 \%$ of water reserves in the adsorption phase in vapour-dominated $\left(\mathrm{T}>300^{\circ} \mathrm{C}\right)$ geothermal systems.

The adsorption process may largely be distinguished from surface adsorption observed in the chemical labs. The main two differentiating reasons are:

- the existence of capillary condensation phenomena in the narrow pores

- the possibility of blocked flow access in the porous network.

The adsorption and capillary effects are complementary phenomena. In the areas where the interfacial surface tension is falling, a greater impact of adsorption forces may be observed (i.e. near critical point).

Figure 2: Adsorption film thickness (t) for mega- and mesopore structure of tight rocks (based upon Gregg and Sing (1982) data in Shang et al. (1995) paper) (p" - saturation pressure, $p$ - gas phase pressure)

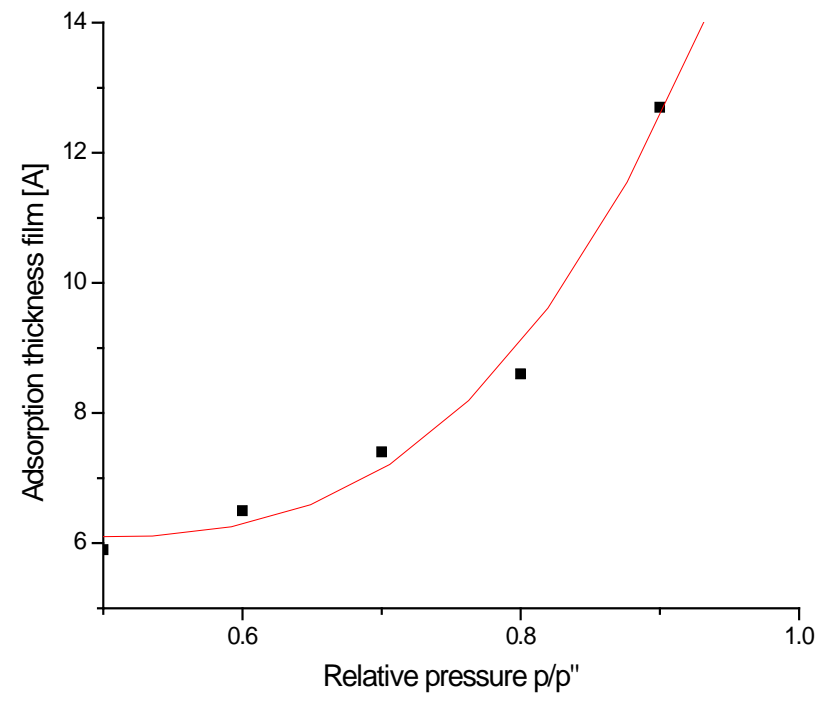

Source: Nagy S. (2002)

Example of capillary-adsorption vapour-liquid equilibrium (VLE) model

In the curved surface inside of porous media for stationary state of second kind (based upon Prigogine definition) following set of equation is valid (neglecting gravity force):

$$
\begin{aligned}
& p_{v}\left(T_{v}, \mu_{1}, \mu_{2}, \ldots, \mu_{n c}\right)-p_{l}\left(T_{l}, \mu_{1}, \mu_{2}, \ldots, \mu_{n c}\right)=\frac{2 \cdot \sigma\left(p_{v}, T_{v}, \mu_{1}, \mu_{2}, \ldots, \mu_{n c}\right)}{r_{e}-t} \\
& T_{v}=T_{l}
\end{aligned}
$$

where T- temperature and $\mu_{\mathrm{i}}$ - chemical potential of $\mathrm{i}$ - component can be varied independently, that $\mathrm{r}$ is allowed to vary at the same time, $\mathrm{t}$ - is the critical adsorption film.

At the dew point of capillary condensation phenomena exist three type of chemical potential: 
or

$$
\mu_{i}^{L}=\mu_{i}^{V}=\mu_{i}^{\operatorname{Vad}}, \mathrm{i}=1, . . \mathrm{nc}
$$

$$
\begin{aligned}
& f_{i}^{L}\left(p_{v}-p_{c}, T, x_{1}, x_{2}, \ldots, x_{n c}\right)-f_{i}^{V}\left(p_{v}, T, x_{1}, x_{2}, \ldots, x_{n c}\right)=0, \mathrm{i}=1, . . \mathrm{nc} \\
& z_{i}-y_{i}=0, \mathrm{i}=1, . . \mathrm{nc} \\
& \sum_{i=1}^{n c} x_{i}-1=0 \quad \sum_{i=1}^{n c} y_{i}-1=0
\end{aligned}
$$

Laplace equation (an other proposal for modification of Laplace equation is presented in paper of Firincinoglu et al. (2012), in this work only classic equation has been used):

$$
p_{v}-p_{l}-\frac{2 \cdot \sigma}{r_{e}-t}=0
$$

Interfacial multicomponent surface tension is calculated using (8) equation:

$$
\sigma^{1 / E}=\frac{p_{v}}{Z^{v} R T} \sum_{i=1}^{n c}\left[\left(\frac{Z^{V}}{Z^{L}}\right) \cdot x_{i}-y_{i}\right] \cdot \pi_{i}
$$

where $\sigma$ - IFT, $Z^{v}, Z^{L}$ - vapor and liquid phase compressibility factor, E- empirical dimensionless constant, $\pi_{\mathrm{i}^{-}}$ parachor of i-component (Danesh, 1991, Weinaug, Katz, 1943)). This set of nonlinear equations (3) may be modified by expanding using Taylor series and taking into consideration only first term, chemical potential of icomponent in the liquid phase may be calculated:

$$
\begin{aligned}
& \mu_{i}^{L}\left(p_{v}-p_{c}(r, t), T, x_{1}, x_{2}, \ldots, x_{n c}\right)= \\
& =\mu_{i}^{L}\left(p_{v}, T, x_{1}, x_{2}, \ldots, x_{n c}\right)-\frac{\partial \mu_{i}^{L}\left(p_{v}, T, x_{1}, x_{2}, \ldots, x_{n c}\right)}{\partial p_{v}} p_{c}(r, t)
\end{aligned}
$$

or using fugacity of i-component for isothermal conditions:

$$
\begin{gathered}
\ln f_{i}^{L}\left(p_{L}, T, x_{1}, x_{2}, \ldots, x_{n c}\right)= \\
=\ln f_{i}^{L}\left(p_{v}, T, x_{1}, x_{2}, \ldots, x_{n c}\right)-\frac{\partial \ln f_{i}^{L}\left(p_{v}, T, x_{1}, x_{2}, \ldots, x_{n c}\right)}{\partial p_{v}} p_{c}(r, \mathrm{t})
\end{gathered}
$$

The derivative on the right side is a molar partial component volume:

$$
\frac{\partial \ln f_{i}^{L}\left(p_{v}, T, x_{1}, x_{2}, \ldots, x_{n c}\right)}{\partial p_{v}}=\frac{\bar{V}_{i}^{L}}{R T}
$$

where $\bar{V}_{i}^{L}$ is partial liquid molar volume o i-component. Equation (10) may be rewritten to the form :

$$
\ln f_{i}^{v}\left(p_{v}, T, y_{1}, y_{2}, \ldots, y_{n c}\right)=\ln f_{i}^{L}\left(p_{v}, T, x_{1}, x_{2}, \ldots, x_{n c}\right)-\bar{V}_{i}^{L} \frac{p_{c}(r, t)}{R T}
$$

Based upon above derivation difference between bulk and capillary condensate dew point equations may be formulate:

$$
\begin{aligned}
& \qquad F\left(N_{v}=1, p_{c}(r, t) \neq 0\right) \equiv 1-\sum_{i=1}^{n c} \frac{Z_{i}}{K_{i}^{\infty}} \cdot \exp \left(\varepsilon_{i} p_{c}(r, t)\right)=0 \\
& \varepsilon_{i}=\frac{V_{i}^{L}}{R \cdot T} \text { - component Poynting factor, } V_{i}^{L} \text {-partial molar liquid component volume. }
\end{aligned}
$$

Based upon (12) equation the new capillary condensation equilibrium constant may be introduced:

$$
\begin{aligned}
& \varepsilon_{i}=\frac{V_{i}^{L}}{R \cdot T}-\text { component Poynting } \\
& \text { upon (12) equation the new capi } \\
& K_{i}=K_{i}^{\infty} \cdot \exp \left(\int_{0}^{p_{c}(r, t)} \varepsilon_{i} d p\right)
\end{aligned}
$$

or after simplification based of constant partial molar volume:

$$
K_{i}=K_{i}^{\infty} \cdot \exp \left(\varepsilon_{i} p_{c}(r, t)\right)
$$


The proposed algorithm for calculation of the capillary condensation dew pressure is given in paper of Nagy (2002) together with new form of Rachford-Rice equation and modified tangent plane criterion for capillary condensation (MTPCCC) based upon fundamental work of Michelsen (1982a, 1982b).

\subsection{Examples of influence of capillary-adsorption effects}

Figure 3: The change of saturation curve in presence of curvature of porous media $\left(\mathrm{T}=366.6^{\circ} \mathrm{K}\right)$

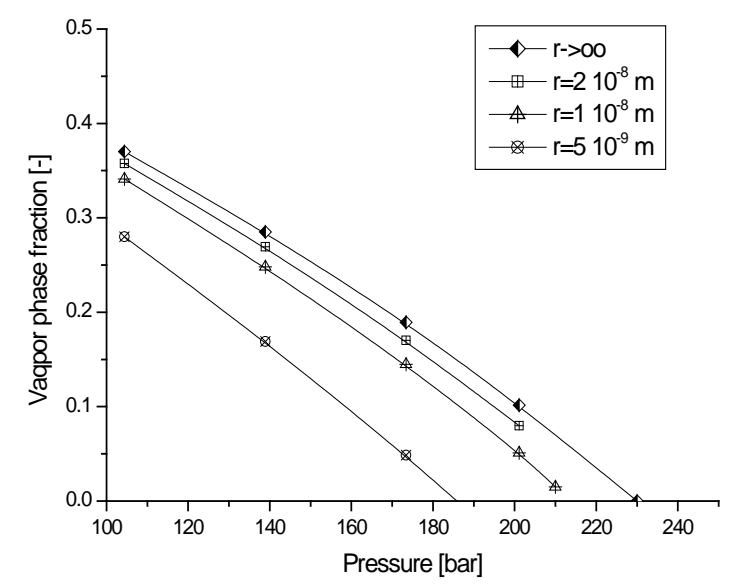

Source: Nagy S. (2002)

Figure 4: Impact of pore radius of porous media on phase boundary movement (mixture 3).

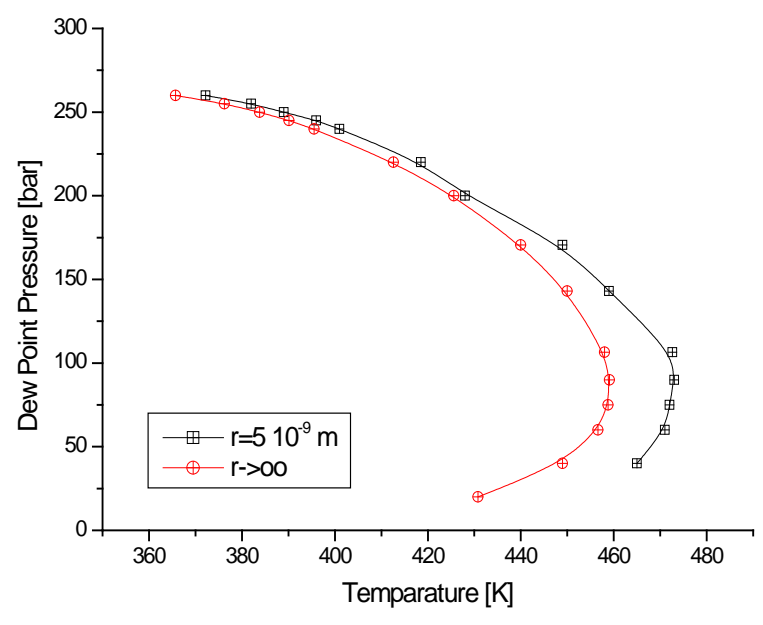

\section{Conclusions}

Source: Nagy S. (2002)

Further work is needed to response the thesis that in reservoirs with a limited porous radius, phase behavior of gas - condensate system occurs in extended range of saturation pressure for a given reservoir temperature. Following further studies are projected:

- construction of a new model of thermodynamic vapor-liquid equilibrium in a porous media with a small porous radius in unconventional reservoirs;

- definition of new criteria for calculation of the vapor-liquid equilibrium including capillary condensation;

- construction of a new algorithm calculating dew curve of capillary condensation in porous rocks;

- presentation of a new form of the balance equation for the area of capillary condensation with adsorption of vapor phase;

- theoretical output will be used in practice to calculate the equilibrium for gas- condensate systems with Peng - Robinson equation;

- construction of a new, efficient algorithm for determining the VLE properties of gas - condensate system in the reservoirs (TGR / SGR) and analytical model which will correct phase equilibrium constants. 


\section{References}

- Chen J-H, Estimation of total hydrocarbon in the presence of capillary condensation for unconventional shale reservoirs, SPE 164468

- Clarkson, C.R. (2013) Modelling of supercritical fluid adsorption on organic-rich shales and coal, SPE 164532

- Danesh A.,S. Dandekar A. Y., Todal A.C. , Sarkar R., 1991, A Modified Scaling Law and Parachor Method Approach for Improved Prediction of Interfacial Tension of Gas-Condensate System, SPE 2270

- Defay R., Prigogine I., (1966). Surface Tension and Adsorption. Longmans, London.

- Economides M.J., F.G. Miller, 1986, Geothermal Reservoir Evaluation Considering Fluid Adsorption and Composition, SPE Res. Eng., March 1986, p. 131-147

- Freeman, C.M. (2012) Measurement, modelling and diagnostics of flow gas composition changes in shale gas wells, SPE 1533991

- Freeman, C.M. (2013) Modelling and performance interpretation of following gas composition changes in shale gas wells with complex fractures, IPTC 17075

- Giamminonni, D. (2010) Condensate Banking Phenomenon evaluation in heterogeneous low permeability reservoirs, SPE 131582

- Michelsen M.L, 1982a, The Isothermal Flash Problem I. Stability analysis, Fluid Phase Equilibria, Vol. 8, p.1-19

- Michelsen M.L, 1982b, The Isothermal Flash Problem I. Phase Split Calculation, Fluid Phase Equilibria, Vol. 8, p. 21-40

- Nagy S. (2002) Capillary adsorption effects in gas condensate systems in tight rocks, Arch. Min. Sci., vol.47 iss. 2, pp. 205-253,

- Nagy S. (2003) Capillary adsorption effects in gas condensate systems in tight rocks - Vertical variation of hydrocarbon composition, Arch. Min. Sci., vol. 48 iss. 3, pp. 355-402

- Nagy S., Siemek J. (2013) Phase Envelope of Gas Condensate System in Nanopores, ICEEICIT2013 (paper reviewed and accepted for publication)

- Pang, J. et. al. (2013) Effect of porous media on saturation pressures of shale gas and shale oil, IPTC 16419

- $\quad$ Peng, D.-Y. and Robinson, D.B. (1976), A New Two-Constant Equation of State, Ind. Eng. Chern. Fund. 15, No.1, 59-64.

- Shang S., Horne R.N., Ramey H., (1995) Water vapor adsorption on geothermal reservoir rocks, Geothermics Vol. 24, No. 4, pp.523-540

- Satik C., Horne R.N., 1995, A Study of Adsorption of Gases in Tight Reservoir Rocks, SPE 30732

- Shang S., Horne R.N., Ramey H., 1995, Water vapor adsorption on geothermal reservoir rocks, Geothermics, Vol. 24, No.4, pp. 523-540,

- Siemek J., Nagy S. (2012) Energy carriers use in the world: natural gas - conventional and unconventional gas resources, Arch of Min. Sci. vol. 57 no. 2 pp. 283-312

- Sigmund P.M., Dranchuk P.M., Morrow N.R., Purris R.A., Retrograde Condensation in Porous Media, SPEJ, 1973

- Smith L.R., Yarborough L., (1968), Equilibrium Revaporization of Retrograde Condensate by Dry Gas Injection, SPEJ, pp. 87-94

- Trebin R.A., Zadora G.I., 1968, Experimental Study of the Effect of Porous Media on Phase Changes in Gas Condensate Systems, Neft i Gaz

- Weinaug C.F., Katz D.L., (1943), Surface Tension of Methane-Propane Mixtures, I\&EC, p. 239246

- Weinang C.F., Cordell J.C., 1949, Revaporization of Butane and Pentane from Sand, Trans. AIME (1949), Vol. 179, p.303-312

- Whitson C. \& Sunjerga S., (2012), PVT in Liquid-Rich Shale Reservoirs, SPE 155499 